\title{
Design Heuristics for Customer-Centric Business Processes
}

\begin{abstract}
Purpose - Customer centricity has evolved into a success factor for many companies, requiring all corporate activities - including business processes - to be aligned with customer needs. With most existing approaches to business process (re-) design focusing on process efficiency, customers are often treated as second-class citizens. Despite emergent research on customer process management, there is a lack of guidance on how to design customer-centric business processes.
\end{abstract}

Design/methodology/approach - We conducted a structured literature review and analyzed companies awarded for outstanding customer centricity to compile design heuristics for customer-centric business processes. We iteratively validated and refined these heuristics with experts from academia and industry. Finally, we grouped the heuristics according to their expected impact on interaction capabilities to enable their prioritization in specific settings.

Findings - We propose 15 expert-approved and literature-backed design heuristics for customer-centric business processes together with real-world examples. The heuristics aim at increasing customer satisfaction with interaction-intensive core processes, which is an important driver of corporate success.

Originality/value - The design heuristics complement existing efficiency-centered (re-) design heuristics. They reflect cognitive shortcuts that support process analysts in the generation of innovative ideas during process (re-) design. The heuristics also add to customer process management and help put customer centricity into practice.

Keywords Business process management, Business process redesign, Business process improvement, Customer centricity, Design heuristics

Paper type Research Paper 